\title{
Bridging the Gap: Collaboration between a School of Pharmacy, Public Health, and Governmental Organizations to provide Clinical and Economic Services to Medicare Beneficiaries
}

Rajul A. Patel, PharmD, PhD; Mary Anne Choi, PharmD Candidate; Dorothy Fan, PharmD Candidate; Vincent Man, PharmD Candidate; Cathy Thao Nguyen, PharmD Candidate; Thanh Thai, PharmD Candidate; Michaela Vachuska, PharmD Candidate; Milana Vachuska, PharmD Candidate; Michael Xu, PharmD Candidate; Cynthia S. Valle-Oseguera, PharmD, APh, BCACP, BCGP; Carly A. Ranson, PharmD, BCGP; Edward L. Rogan, PharmD, BCACP; Mark P. Walberg, PharmD, PhD; Joseph A. Woelfel, PhD, RPh, BCGP; Christopher Pham, PharmD

University of the Pacific

\begin{abstract}
Objective: Promoting healthy communities through the provision of accessible quality healthcare services is a common mission shared by schools of pharmacy, public health departments, and governmental agencies. The following study seeks to identify and detail the benefits of collaboration between these different groups. Methods: In total, 112 mobile clinics targeting Medicare beneficiaries were held in 20 cities across Northern/Central California from 2007 to 2016. Under the supervision of licensed pharmacists, trained student pharmacists provided vaccinations, health screenings, Medicare Part D plan optimization services, and Medication Therapy Management (MTM) to patients at each clinic site. Clinic support was extended by public health departments, governmental agency partners, and a health professional program. Results: Since clinic inception, 8,996 patients were provided services. In total, 19,441 health screenings and 3,643 vaccinations were collectively provided to clinic patients. We assisted 5,549 beneficiaries with their Part $D$ benefit, resulting in an estimated aggregate out-of-pocket drug cost savings of \$5.7 million. Comprehensive MTM services were provided to 4,717 patients during which 8,184 medication-related problems (MRPs) were identified. In 15.3\% of patients, the MRP was determined severe enough to warrant prescriber follow-up. In total, $42.9 \%$ of clinic patients were from racial/ethnic minority groups and $25.5 \%$ had incomes $\leq 150 \%$ of the Federal Poverty Level. Conclusion: Collaboration between a school of pharmacy, public health departments, and governmental organizations can effectively serve Medicare beneficiary populations and result in: 1) lower out-ofpocket drug costs, 2) minimization of medication-related problems, 3) increased vaccination uptake, and 4) increased utilization of health screenings.
\end{abstract}

Key words: Medicare, Collaborations/Interprofessional education, Public Health, Medication Therapy Management, Health Screenings/Vaccinations

\section{Background}

Healthy People 2020 provides national objectives for improving the health of Americans through a multidimensional approach that involves organizational and community collaboration, empowers individuals to make informed health decisions, and measures the impact of preventative activities. ${ }^{1}$

Healthy People 2020 consists of key topic areas including improving access to health care services, increasing immunization rates, optimizing health outcomes for older adults, solidifying public health infrastructure, and creating environments that reduce the impact of social determinants on health. Promoting healthy communities through the provision of accessible, high-quality health care is a mission

Corresponding author: Christopher Pham, PharmD,

MS/Fellow Graduate Student

Thomas J. Long School of Pharmacy and Health Sciences

University of the Pacific

757 Brookside Road, Stockton, CA 95211

Phone: (408) 609-4625; Email: c_pham9@u.pacific.edu shared by schools of pharmacy, public health departments, and governmental agencies. ${ }^{2}$ Previous research has demonstrated tangible benefits of intergroup collaboration including expanded vaccination access, point-of-care testing, information sharing, and improved care for vulnerable populations. $^{2,3}$

Medicare beneficiaries represent a growing population, many of whom incur high annual healthcare expenditures. There are currently close to 58 million Medicare beneficiaries, $84 \%$ of whom are 65 years of age or older. ${ }^{4}$ In 2012, per capita health care expenditures for adults 65 years of age and older were approximately three times higher than they were for younger patients. ${ }^{5}$ Prescription drug expenditures are the third largest cost driver of healthcare expenditures, with Medicare spending an average of $\$ 2,203$ per beneficiary in 2015 on outpatient prescription drugs. ${ }^{6}$

Medicare Part $D$ is the outpatient prescription drug benefit available to beneficiaries. Patel et al. sought to examine the potential out-of-pocket (OOP) cost savings a beneficiary could realize by optimizing their Part D plan. ${ }^{7}$ It was found that $89.7 \%$ of beneficiaries could reduce their OOP cost by switching to a different Part D plan for the upcoming year. ${ }^{7}$ Cutler et al. 
performed a cross-sectional study including 1,300 beneficiaries with annual incomes less than $300 \%$ of the Federal Poverty Level who received Medicare Part D assistance at community outreach events and found that OOP costs were, on average, reduced by $68 \%$ following counseling recommendations. ${ }^{8}$ Findings from these studies demonstrate that community outreach targeting Medicare beneficiaries can help optimize Part D plan selection and significantly reduce OOP prescription drug costs.

Aside from high OOP drug costs, the complexity of medication regimens can also negatively affect medication adherence and patient outcomes. ${ }^{9}$ Americans age 65 years and older take a median of four prescription medications a month, and $39 \%$ take five or more. ${ }^{10,11}$ As such, many Medicare beneficiaries face a high drug burden and stand to benefit from Medication Therapy Management (MTM) services. During an MTM intervention, a pharmacist or qualified healthcare provider reviews a patient's medication regimen, discusses their concerns/findings with the patient, and addresses any medication-related problems (MRPs). By meeting certain eligibility criteria, Medicare beneficiaries can qualify for receipt of these services through their Part D plan. In 2014, around $8 \%$ of beneficiaries or 2.5 million individuals were eligible for MTM services through their Part D benefit. ${ }^{12}$ Despite the availability of MTM services, drug therapy for many beneficiaries may still be suboptimal. The Centers for Medicare \& Medicaid Services (CMS) found that only $10 \%$ of participating beneficiaries receive a comprehensive medication review, a required component of MTM programs, each year. ${ }^{12}$

The underutilization of MTM services is troubling since MTM has been shown to be effective in improving medication adherence and reducing adverse drug events in the elderly. ${ }^{13}$ A 2010 study conducted by the Department of Health and Human Services reported that $42 \%$ of adverse events experienced by hospitalized Medicare beneficiaries were due to medications. ${ }^{14}$ Moreover, Viswanathan et al. found that over $40 \%$ of severe drug events were preventable. ${ }^{15}$ Lindblad et al. conducted a study including 1,340 veterans which found that $15.3 \%$ of them experienced a drug-disease state interaction. ${ }^{16}$

Medication Therapy Management programs can improve disease state outcomes by optimizing medication regimens and improving adherence. Theising et al. found that receiving MTM services led to reduced blood sugar levels in patients with diabetes and lower blood pressure in those with hypertension. ${ }^{17}$ Perloth et al. found that beneficiaries with congestive heart failure, chronic obstructive pulmonary disease (COPD), and/or diabetes who received MTM services had $11 \%-40 \%$ higher medication adherence rates compared to those who did not receive MTM services. ${ }^{18}$ These studies highlight the potential value of MTM interventions.
Immunizations and preventative health screenings for chronic conditions such as diabetes, hypertension, and osteoporosis can also be beneficial in maintaining the health and well-being of Medicare beneficiaries. Influenza and pneumonia represent the eighth-leading cause of death among adults age 65 years and older in the United States, accounting for 44,836 deaths of the elderly in 2014. ${ }^{19}$ Although influenza and pneumonia are largely preventable, vaccination rates remain subpar. In 2015, the Centers for Disease Control and Prevention (CDC) reported that $63.4 \%$ of adults age 65 years and older received a flu vaccine in the previous year, and $63.6 \%$ had received a pneumococcal vaccine in their lifetime. ${ }^{20}$

Immunization uptake has plateaued over the last decade and remains far short of the $90 \%$ coverage goal for each vaccine set by Healthy People 2020. ${ }^{21-23}$ Recommendations were made in 2014 for adults age 65 years and older to receive both pneumococcal vaccines, however uptake has been slow with only $18.3 \%$ of adults receiving both vaccines two years after the recommendation..$^{23}$ Local public health departments have attempted to increase flu vaccine uptake in underserved populations through partnerships with community-based organizations and hosting vaccine outreach clinics. High patient satisfaction and increased vaccination uptake show that such collaborations can be fruitful. ${ }^{24}$

Existing collaborations between pharmacy and public health have proven beneficial in helping address unmet public health needs. During the H1N1 pandemic in 2009-2010, a collaboration between pharmacies and a local health department in Palm Beach County, Florida helped distribute vaccines and educate patients. This collaboration resulted in the distribution of 200,000 flu information cards to 250 community pharmacies and in-store health clinics by local public health departments. Of those surveyed, $90 \%$ of pharmacy managers reported being asked about influenza by their customers, and $64 \%$ of pharmacy managers reported finding the local health department a useful resource. ${ }^{25}$ The growth of pharmacy and public health collaborations in recent years has sparked interest in policy changes to ensure that pharmacy-based public health services can be effective and sustainable.

Other collaborative programs have been developed with the intent of addressing the health care needs of underserved populations. The Health Disparities Collaborative and the Healthy Communities Access Program were initiated in response to the growing disparity of health care access for different populations. ${ }^{26}$ In addition to local health department collaborations, partnerships between public health and schools of pharmacy have been created to offer students patient education opportunities. "AdvoCaring," a program established at Notre Dame of Maryland University's Pharmacy School, provides free health services such as blood pressure monitoring and educational sessions on select health topics to 
populations in need through partnerships with local agencies. $^{27}$

Medicare beneficiaries stand to benefit from collaborations between schools of pharmacy, public health departments, and governmental agencies. In this paper, we describe a collaborative approach between a School of Pharmacy, multiple public health departments, and different governmental agencies to assist Medicare beneficiaries in lowering their OOP drug costs, ensuring safe and effective use of their medications through provision of MTM services, and improving access to vaccinations and preventive health screenings.

\section{Methods}

In total, 112 mobile health clinics targeting Medicare beneficiaries (Mobile Medicare Clinics) were conducted by the University of the Pacific Thomas J. Long School of Pharmacy and Health Sciences during the annual fall Medicare open enrollment window between 2007 and 2016. All clinics occurred at locations throughout northern and central California. The clinics began by offering only Medicare Part D plan optimization services and expanded over the years to include MTM, vaccinations, and a myriad of free health screenings. All screenings and services were provided by trained pharmacy students under the supervision of licensed pharmacists.

Medicare Part D plan optimization included evaluating a beneficiary's Part D drug plan and identifying if a lower cost plan was available by inputting beneficiary specific information (e.g., medication regimen, preferred pharmacy) into the online Medicare Plan Finder Tool (available at www.medicare.gov). Potential OOP cost savings opportunities, by switching Part D plans, were recorded for each assisted beneficiary.

In 2010, the Mobile Medicare Clinics expanded to include MTM services. The provision of MTM services for assisted beneficiaries included a systematic 12-point process during which the following MRPs were evaluated: 1) expired/out-ofdate medication(s), 2) untreated condition(s), 3) therapeutic duplication(s), 4) medication(s) without indication, 5) contraindication(s), 6) potentially inappropriate medication(s) for older adults, 7) drug-drug interaction(s), 8) drugdisease/condition interaction(s), 9) awareness of the purpose of each medication, 10) how patient reported taking each medication as compared to labeled directions, 11) adverse drug reaction(s), and 12 ) the availability of cheaper therapeutic alternative(s). Drug information databases including Lexicomp ${ }^{\oplus}$, Clinical Pharmacology ${ }^{\oplus}$, UpToDate ${ }^{\oplus}$, Facts and Comparisons ${ }^{\oplus}$, and Micromedex ${ }^{\oplus}$ were consulted to help facilitate each MTM intervention. The type and frequency of each MRP was recorded during each MTM intervention. Student findings were presented to a supervising licensed pharmacist during each intervention and a determination was made as to the severity of each identified MRP. With patient consent, prescribers were notified of all severe MRPs. Demographic data (e.g., race/ethnicity, income, etc.) were collected from each assisted beneficiary during the Part $D$ and/or MTM intervention via a standardized data collection tool that was approved by the University's Institutional Review Board.

In addition to Part D and MTM services, the clinics expanded to provide vaccinations (first introduced in 2010) and health screenings (first introduced in 2011). Immunizations including influenza, pneumococcal (both PCV13 and PPSV23), zoster, and Tdap vaccines have been available at clinic sites. Diabetes and cholesterol screening, blood pressure testing, bone mineral density testing, falls risk assessment, anemia testing, memory decline screening, depression screening, asthma/COPD screening, insomnia screening, and anxiety testing have also been made available at clinic sites.

Our Mobile Medicare Clinics sought collaborative opportunities with strategic partner groups over the years. Partnerships were forged with the following governmental agencies: Health Insurance Counseling \& Advocacy Program (HICAP), County Public Health Departments, CMS, Social Security Administration (SSA), and California Department of Aging (CDA). In addition, partnerships with Clinic host sites and other professional programs [University of San Francisco (USF) Nurse Practitioner Program] have also been cultivated. The nature of these partnerships and the support provided by each partner group can be found in Table 1.

\section{Results}

In aggregate, 8,996 patients were assisted at Clinic sites between 2007 and 2016. In total, $42.9 \%$ of patients selfidentified as belonging to a racial and/or ethnic minority group, and $25.5 \%$ had incomes less than or equal to $150 \%$ of the Federal Poverty Level.

Part D optimization services were provided to 5,549 beneficiaries since the inception of the Clinics. It was observed that $76.3 \%$ of assisted beneficiaries had the potential to lower their OOP costs by switching Part D drug plans in the upcoming year (Table 2). In aggregate, beneficiaries could realize \$5.7 million (or $\$ 1,031 /$ beneficiary per annum) by switching Part $D$ plans during the annual Medicare Part D open enrollment period. Mean potential OOP savings through Part D plan optimization services increased with time, growing at an average rate of $11.1 \%$ per year. In addition, there was a $154 \%$ increase in the number of Medicare beneficiaries assisted with Part D plan optimization services since the partnership with CMS first began.

In total 4,717 patients were provided MTM services at Clinic sites between 2010 and 2016. A total of 8,184 MRPs were identified, or roughly 1.74 MRPs/MTM intervention (Table 3). 
Approximately $15.3 \%$ of patients who were provided with MTM services had a severe MRP that warranted prescriber contact and follow-up. A noticeable increase in MRPs identified per patient was observed since the interprofessional collaboration with USF's nurse practitioner program began in 2015.

In total, 3,643 vaccines $(72.9 \%$ of which were for the flu vaccine) were administered to Clinic patients. The number of vaccines provided to Clinic patients increased between $106 \%$ and $225 \%$ each year since the partnership with County Public Health was first forged. The number of health screenings (e.g., blood glucose, blood pressure, and cholesterol testing) totaled 19,441 at Clinic sites between 2011 and 2016 (Table 4). As such, on average 3,240 free health screenings were provided to the community each year and the average patient took advantage of 2.5 such screenings during their attendance at a Clinic site.

\section{Discussion}

There was a $1,815 \%$ increase in the number of Clinic patient attendees from 2007 to 2016 . The exponential growth in those served is most likely attributable to the support, and collaborative nature, of our external partners.

With regard to Part $D$ plan optimization, the number of beneficiaries assisted grew every year since the CMS partnership began in 2011 (Table 1). The most likely reason for the observed growth is that CMS's onsite/phone support during Clinics enabled more efficient beneficiary eligibility verification. This significantly reduced the average length of time per intervention and allowed for a greater number of beneficiaries to receive Part $D$ services at each Clinic site. The fact that a smaller (72.8\% vs. $95.2 \%$ ) percentage of patients were observed to have potential OOP cost-savings by switching Part D plans in 2016 versus 2007 is likely attributable to the number of plan offerings. In 2007, there were 55 standalone Part D prescription drug plans available in California. In contrast, there were only 24 such plans in $2017 .{ }^{28}$ The decrease in plan offerings means that beneficiaries now have fewer plans from which to choose that could result in lower OOP cost savings.

The number of patients receiving MTM services consistently increased every year the service was offered (Table 3). There was a notable increase in the average number of MRPs identified per MTM intervention starting 2014 and continuing through 2016. We posit that this uptick occurred because of the interprofessional collaboration with the USF Nurse Practitioner program. Starting in 2014, nurse practitioner students assisted pharmacy students in providing the MTM intervention and helped collect medical and medication information from the patient while drawing on their own expertise and training focus. This comprehensive approach was much more thorough than that which would be possible by any one type of health care professional student alone. Despite the increase in the number of MRPs identified, the percentage of severe MRPs remained constant during this time. This suggests that the collaboration mostly helped identifying problems that were less severe in nature and/or that once identified and addressed it was unlikely that those same severe MRPs would be found when patients returned the following year.

The number of vaccines administered in a given year increased from 208 to 677 following collaboration with Public Health (Table 4). In a typical year, between 150 and 250 doses of the flu vaccine were secured from County Public Health departments. This flu vaccine supply enabled us to provide the influenza vaccine to Clinic patients regardless of their insurance coverage or ability to pay. The number of administered pneumococcal vaccinations increased by $44 \%$ from 2013 to 2015 and made up about 30\% of provided vaccinations in 2015. The pneumococcal vaccine uptake increased and plateaued with a peak in 2015 which is likely attributable to the 2014 CDC recommendations to provide adults age 65 years and older with one dose of each vaccine (13-valent pneumococcal conjugate vaccine [PCV13] and the 23-valent pneumococcal polysaccharide vaccine [PPSV23]) six to twelve months apart. ${ }^{29}$ While there has been an overall increase in vaccines administered since 2010, a steady decline from 2013 has been observed. A plausible reason for this finding is that once patients have received the shingles, Tdap and both pneumococcal vaccines they have been brought upto-date and thus only need an annual flu vaccine. Vaccine delivery and uptake are multifactorial and requires much more logistical, financial and faculty support to ensure its growth and sustainability compared to lower cost health screenings or cognitive services (e.g., MTM).

Partnership between a school of pharmacy, governmental health organizations, community partners and other health professional programs can effectively provide much-needed health care screenings/services to underserved and underrepresented communities. In doing so, collaborations of this type have the potential to reduce OOP health care costs, promote medication safety, improve access to preventative health screenings, and aid communities in achieving public health goals. Viewing this collaborative model in the frame of pharmacy education can transform the way students perceive current healthcare challenges and integrate their skills to effectuate change. Raising student awareness of public health is key to improving healthcare access to underserved communities. By partnering with public health, pharmacy students have the opportunity to participate in public health initiatives and provide services that can benefit targeted communities. $^{30}$

In November 2015, recognizing the increasing synergy between public health and pharmacy, the American Public 
Health Association's Governing Council approved the development of a Pharmacy Public Health Special Primary Interest Group (SPIG). This group focused on advancing the pharmacist's role in promoting public health, encouraging safe medication use, and improving patient outcomes. Due to an aging population and rising healthcare costs, pharmacists and by extension, pharmacy students are well positioned to have a meaningful role impacting patient care. Offering services such as Part D optimization, MTM, vaccinations and health screenings can help reduce patient and the healthcare system costs, increase medication adherence, and improve health outcomes.

One limitation of this study is the exploratory nature of the outcomes measured, such as potential savings and MRPs identified as opposed to realized savings or hospitalizations avoided. Due to the nature of the mobile health clinics, there was no quantitative way to measure the impact of each individual organization. Further research is needed to determine the impact of services provided on the public health sector as well as clinical and economic benefits.

\section{Conclusion}

This study described the nature of support and resultant outcomes from a collaborative approach between a school of pharmacy, public health, and governmental organizations to improve the economic and clinical outcomes of communitydwelling Medicare beneficiaries. We found that the number of patients served increased greatly through this collaborative approach and benefits to Clinic attendees included lower OOP drug costs, identification and minimization of medicationrelated problems, increased vaccine uptake and increased utilization of preventative healthcare screenings.

\section{Acknowledgements: None}

Conflict of Interest: We declare no conflicts of interest or financial interests that the authors or members of their immediate families have in any product or service discussed in the manuscript, including grants (pending or received), employment, gifts, stock holdings or options, honoraria, consultancies, expert testimony, patents and royalties.

Treatment of Human Subjects: IRB review/approval required and obtained

\section{References}

1. U.S. Department of Health and Human Services, Office of Disease Prevention and Health Promotion. Healthy people 2020. Healthy People 2020 Web site. https://www.healthypeople.gov/2020/AboutHealthy-People. Published 2014. Updated 2017. Accessed February 24, 2017.

2. Roberts G, Rubin S, Smith J, Adams A, Klepser D. Public health perceptions of community pharmacy partnership opportunities. J Public Health Management Practice. 2015;21(4):413-415.

3. DiPietro Mager N, Farris K. The importance of public health in pharmacy education and practice.

American Journal of Pharmaceutical Education. 2016;80(2):1-2.

4. Medicare enrollment dashboard. CMS.gov Web site. https://www.cms.gov/Research-Statistics-Data-andSystems/Statistics-Trends-andReports/Dashboard/MedicareEnrollment/Enrollment\%20Dashboard.html. Updated 2017. Accessed April 20, 2017.

5. U.S. Department of Health and Human Services. 2012 CMS statistics. . 2012;03504.

6. Cubanski J, Neuman T. The facts on medicare spending and financing. The Henry J. Kaiser Family Foundation Web site. http://www.kff.org/medicare/issue-brief/the-factson-medicare-spending-and-financing/. Published July 18, 2017. Updated 2017. Accessed February 24, 2017.

7. Patel R, Lipton H, Cutler T, Smith A, Tsunoda S, Stebbins M. Cost minimization of medicare part $D$ prescription drug plan expenditures. The American Journal of Managed Care. 2009;15(8):545-552.

8. Cutler T, Stebbins M, Smith A, et al. Promoting access and reducing expected out-of-pocket prescription drug costs for vulnerable medicare beneficiaries: A pharmacist-directed model. Medical Care. 2011;49(4):343-347.

9. Fried T, O'Leary J, Towle V, Goldstein M, Trentalange M, Martin D. Health outcomes associated with polypharmacy in community-dwelling older adults: A systematic review. J Am Geriatr Soc. 2014;62(12):2261-2272.

10. Charlesworth C, Smit E, Lee D, Alramadhan F, Odden M. Polypharmacy among adults aged 65 years and older in the united states: 1988-2010. J Gerontolog $A$ Bio Sci Med Sci. 2015;70(8):989-995. 
11. Kantor E, Rehm C, Haas J. Trends in prescription drug use among adults in the united states from 19992012. JAMA. 2015;314(17):1818-1831.

12. CMS. Medicare program; contract year 2015 policy and technical changes to the medicare advantage and the medicare prescription drug benefit programs. Federal Register. 2014;79(7):1918-2073.

13. Burke LA, Ryan AM, The Complex Relationship between Cost and Quality in US Health Care. AMA Journal of Ethics. 2014;16(2):124-130.

14. Department of Health and Human Services., Levinson D. Adverse events in hospitals: National incidence among medicare beneficiaries. 2010.

15. Viswanathan M, Kahwati LC, Golin CE, et al. Medication Therapy Management Interventions in Outpatient Settings: A Systematic Review and Metaanalysis. JAMA Intern Med. 2015;175(1):76-87. doi:10.1001/jamainternmed.2014.5841

16. Lindblad C, Hanlon J, Gross C, et al. Clinically important drug-disease interactions and their prevalence in older adults.Clin Ther. 2006;28(8):1133-1143.

17. Theising K, Fritschle T, Schlofield A, Hicks E, Schymik M. Implementation and clinical outcomes of an employer-sponsored, pharmacist-provided medication therapy management program. Pharmacotherapy. 2015;35(11):e159-163.

18. Perlroth D, Marrufo G, Montesinos A, et al. Medication therapy management in chronically ill populations: Final report. Burlingame, CA: Acumen, LLC. 2013.

19. Kochanek DK, Murphy LS, Xu J, et al. National vital statistics reports: Deaths: Final data for 2014. NVSS. 2016;4(65).

20. National Center for Health Statistics. Health, United States, 2015: With Special Feature on Racial and Ethnic Health Disparities. Hyattsville, MD. 2016. 2016.

21. National Center for Health Statistics. Health, United States, 2013: With Special Feature on Prescription Drugs. Hyattsville, MD. 2014. (CDC 2013)
22. National Center for Health Statistics. Health, United States, 2016: With Chartbook on Long-term Trends in Health. Hyattsville, MD. 2017. (CDC 2016)

23. Hall V, Banerjee E, Kenyon C. Centers for disease control and prevention: Morbidity and mortality weekly report. MMWR. 2017;27(66).

24. Mobasher Z, Smith L, Stegall A, et al. Communitybased flu outreach clinics in south los angeles: Client satisfaction and experiences. Public Health Nurse. 2017;34(3):276-285.

25. Rosenfeld L, Etkind P, Grasso A. Extending the reach: Local health department collaboration with community pharmacies in palm beach county, florida for H1N1 influenza pandemic response. JPHMP. 2011. 17(5):439-448.

26. Shi L, Collins P. Public-private partnerships in community health centers: Addressing the needs of underserved populations. Organizational Ethics. 2007;4(1).

27. Fritsch $\mathrm{M}$, Culver N, Culhane N, Thigpen J, Lin A. AdvoCaring: A cocirricular program to provice advocacy and caring to underserved populations in baltimore. American Journal of Pharmaceutical Education. 2016;80(7):1-8.

28. Q1 Group LLC. 2017 stand-alone medicare part D prescription drug plans. Q1Medicare.com Web site. https://q1medicare.com/PartD-SearchPDPMedicare2017PlanFinder.php?state $=C A \&$ addinfo $=\&$ LIS $=$ \&only $\underline{5=\& \text { stars } 5=\& \text { natOnly=\&plans=\&plans } 2=\& \text { sort }=\text { premi }}$

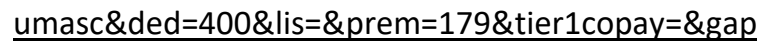
=\&utm source=partd\&utm medium=pdpfinder\&ut m campaign=link2chart. Updated 2017. Accessed July 19, 2017, 2017.

29. Black C, Yue X, Ball S. Centers for disease control and prevention: Morbidity and mortality weekly report. MMWR. 2014;63(37).

30. Dindial S, Fung C, Arya V. A call for greater policy emphasis and public health applications in pharmacy education. American Journal of Pharmaceutical Education. 2012;76(8):1-2. 
Table 1. Clinic Partners and the Nature of their Provided Support Either Prior to and/or During Each Mobile Medicate Clinic

\begin{tabular}{|c|c|c|}
\hline $\begin{array}{l}\text { Partners } \\
\text { (first year of } \\
\text { partnership) }\end{array}$ & Prior to Clinic & At Clinic \\
\hline $\begin{array}{l}\text { Health Insurance } \\
\text { Counseling \& } \\
\text { Advocacy Program } \\
\text { (2007) }\end{array}$ & $\begin{array}{l}\text { - } \quad \text { Assisted in disseminating Clinic flyers } \\
\text { throughout the community } \\
\text { - } \quad \text { Helped establish new Clinic host sites }\end{array}$ & $\begin{array}{l}\text { Provided in-person Clinic support to answer } \\
\text { beneficiary questions about Medicare } \\
\text { Advantage plan offerings in their county, } \\
\text { Medigap policies, and Medicare's general } \\
\text { benefit structure }\end{array}$ \\
\hline $\begin{array}{l}\text { County Public Health } \\
\text { Services (2010) }\end{array}$ & $\begin{array}{l}\text { - Hosted focus groups to test the effectiveness } \\
\text { of Clinic marketing material } \\
\text { - } \quad \text { Funded event(s) flyer production and } \\
\text { distribution to increase awareness of Clinics } \\
\text { - } \quad \text { Advertised Clinics throughout the community } \\
\text { - } \quad \text { Funded a sensitivity training program for } \\
\text { pharmacy students }\end{array}$ & $\begin{array}{l}\text { - Supplied influenza vaccines for county } \\
\text { residents }\end{array}$ \\
\hline $\begin{array}{l}\text { Centers for Medicare } \\
\& \text { Medicaid Services } \\
\text { (2011) }\end{array}$ & $\begin{array}{l}\text { - Assisted in disseminating Clinic flyers } \\
\text { throughout the community }\end{array}$ & $\begin{array}{l}\text { - Provided direct support during each Clinic to } \\
\text { assist in beneficiary eligibility verification and } \\
\text { technical questions }\end{array}$ \\
\hline $\begin{array}{l}\text { Social Security } \\
\text { Administration } \\
\text { (2012) }\end{array}$ & & $\begin{array}{l}\text { - } \quad \text { Provided onsite Clinic support for } \\
\text { beneficiaries needing help in applying for the } \\
\text { Low-Income Subsidy (LIS) }\end{array}$ \\
\hline $\begin{array}{l}\text { California } \\
\text { Department of Aging } \\
(2012)\end{array}$ & $\begin{array}{l}\text { - Assisted in disseminating Clinic flyers } \\
\text { throughout the community } \\
\text { Provided grant funding to help subsidize the } \\
\text { cost of Clinic offerings }\end{array}$ & $\begin{array}{l}\text { - Provided onsite Clinic support to share } \\
\text { resources available to beneficiaries }\end{array}$ \\
\hline $\begin{array}{l}\text { University of San } \\
\text { Francisco (USF) } \\
\text { Nurse Practitioner } \\
\text { Program (2014) }\end{array}$ & $\begin{array}{l}\text { - } \quad \text { Participated in simulation exercises to } \\
\text { prepare students (pharmacy and nurse } \\
\text { practitioners) for interprofessional } \\
\text { collaborative patient care at Clinic sites }\end{array}$ & $\begin{array}{l}\text { - Provided interprofessional collaboration } \\
\text { during Clinic MTM interventions }\end{array}$ \\
\hline $\begin{array}{l}\text { Individual Clinic Host } \\
\text { Sites }\end{array}$ & $\begin{array}{l}\text { - } \quad \text { Coordinated Clinic patient appointments } \\
\text { - } \quad \text { Provided assistance with Clinic advertisement } \\
\text { - } \quad \text { Educated students on effective } \\
\text { communication and cultural awareness of the } \\
\text { target population }\end{array}$ & $\begin{array}{ll} & \text { Provided venue space } \\
\text { - } & \text { Provided logistical support } \\
\text { - } & \text { Provided food for volunteers }\end{array}$ \\
\hline
\end{tabular}


Table 2. Resultant Outcomes from Medicare Part D Plan Optimization Services from 2007-2016

\begin{tabular}{|c|c|c|c|c|c|c|c|c|c|c|}
\hline \multicolumn{11}{|c|}{ Year } \\
\hline & 2007 & 2008 & 2009 & 2010 & 2011 & 2012 & 2013 & 2014 & 2015 & 2016 \\
\hline $\begin{array}{l}\text { Number of } \\
\text { Clinics }\end{array}$ & 6 & 8 & 11 & 9 & 13 & 12 & 14 & 13 & 13 & 13 \\
\hline $\begin{array}{l}\text { Number of } \\
\text { patients } \\
\text { assisted with } \\
\text { Part D }\end{array}$ & 72 & 315 & 286 & 395 & 540 & 621 & 676 & 754 & 888 & 1,002 \\
\hline $\begin{array}{l}\text { Patients with } \\
\text { potential OOP } \\
\text { cost savings } \\
\text { by switching } \\
\text { Part D plans } \\
(\%)\end{array}$ & 95.2 & 85.8 & 77.8 & 75.2 & 81.2 & 80.2 & 77.7 & 69.4 & 74.5 & 72.8 \\
\hline $\begin{array}{l}\text { Total } \\
\text { potential OOP } \\
\text { savings by } \\
\text { switching Part } \\
\text { D plans (\$) }\end{array}$ & 35,696 & 146,627 & 140,276 & 174,688 & 368,660 & 713,502 & 660,315 & $1,043,429$ & $1,320,073$ & $1,121,370$ \\
\hline $\begin{array}{l}\text { Avg. annual } \\
\text { potential OOP } \\
\text { savings per } \\
\text { patient (\$) }\end{array}$ & 496 & 646 & 754 & 562 & 814 & 1,149 & 972 & 1,628 & 1,487 & 1,282 \\
\hline
\end{tabular}

OOP=out-of-pocket Avg.=average

Table 3. Medication Therapy Management (MTM) Services and Identified Medication Related Problems (MRP's) from 2007 to 2016

\begin{tabular}{|l|c|c|c|c|c|c|c|c|c|c|}
\hline & $\mathbf{2 0 0 7}$ & $\mathbf{2 0 0 8}$ & $\mathbf{2 0 0 9}$ & $\mathbf{2 0 1 0}$ & $\mathbf{2 0 1 1}$ & $\mathbf{2 0 1 2}$ & $\mathbf{2 0 1 3}$ & $\mathbf{2 0 1 4}$ & $\mathbf{2 0 1 5}$ & $\mathbf{2 0 1 6}$ \\
\hline $\begin{array}{l}\text { Number of MTM services } \\
\text { provided }\end{array}$ & & & & & & & & & & \\
\hline & - & - & - & 339 & 543 & 583 & 659 & 731 & 865 & 997 \\
\hline $\begin{array}{l}\text { Total MRPs identified } \\
\text { Avg. MRP per patient }\end{array}$ & - & - & - & 1.5 & 0.8 & 1.7 & 1.2 & 1.6 & 1,992 & 2,348 \\
\hline & & & & & & & & & & \\
Total severe MRPs & & & & & & & & & & \\
identified \\
$\begin{array}{l}\text { (\%) of MRPs identified } \\
\text { severe }\end{array}$ & - & - & - & 78 & 103 & 62 & 137 & 79 & 102 & 162 \\
\hline
\end{tabular}

$\mathrm{MRP}=$ medication related problems MTM=medication therapy management Avg.=average 
Table 4. Vaccine Administration and Aggregate Health Screenings Provided at Clinic Sites from 2007 to 2016

\begin{tabular}{|c|c|c|c|c|c|c|c|c|c|c|}
\hline & 2007 & 2008 & 2009 & 2010 & 2011 & 2012 & 2013 & 2014 & 2015 & 2016 \\
\hline Total clinic patients & 72 & 315 & 286 & 401 & 1,013 & 1,547 & 1,279 & 1,369 & 1,335 & 1,379 \\
\hline Total vaccines administered & - & - & - & 208 & 429 & 563 & 677 & 629 & 612 & 525 \\
\hline $\begin{array}{l}\text { Flu } \\
\text { Number administered } \\
\text { (\%) of total vaccines }\end{array}$ & - & - & - & $\begin{array}{l}208 \\
100 \\
\end{array}$ & $\begin{array}{l}294 \\
68.5 \\
\end{array}$ & $\begin{array}{c}441 \\
78.3 \\
\end{array}$ & $\begin{array}{l}491 \\
72.5 \\
\end{array}$ & $\begin{array}{l}436 \\
69.3\end{array}$ & $\begin{array}{l}397 \\
64.9 \\
\end{array}$ & $\begin{array}{l}387 \\
73.7 \\
\end{array}$ \\
\hline $\begin{array}{l}\text { Pneumococcal } \\
\text { Number administered } \\
\text { (\%) of total vaccines }\end{array}$ & - & - & - & - & $\begin{array}{c}59 \\
13.8\end{array}$ & $\begin{array}{c}74 \\
13.1\end{array}$ & $\begin{array}{c}125 \\
18.5\end{array}$ & $\begin{array}{l}138 \\
21.9\end{array}$ & $\begin{array}{c}180 \\
29.4\end{array}$ & $\begin{array}{l}122 \\
23.2\end{array}$ \\
\hline $\begin{array}{l}\text { Tdap or Zoster } \\
\text { Number administered } \\
(\%) \text { of total vaccines }\end{array}$ & - & - & - & - & $\begin{array}{c}76 \\
17.7 \\
\end{array}$ & $\begin{array}{l}48 \\
8.5 \\
\end{array}$ & $\begin{array}{r}61 \\
9.0 \\
\end{array}$ & $\begin{array}{l}55 \\
8.7 \\
\end{array}$ & $\begin{array}{l}35 \\
5.7 \\
\end{array}$ & $\begin{array}{l}16 \\
3.0\end{array}$ \\
\hline $\begin{array}{l}\text { Health screenings } \\
\text { Number provided } \\
\text { Avg. screenings per patient }\end{array}$ & - & - & - & - & $\begin{array}{c}2,270 \\
2.2\end{array}$ & $\begin{array}{c}2,886 \\
1.9\end{array}$ & $\begin{array}{c}3,223 \\
2.5\end{array}$ & $\begin{array}{c}3,775 \\
2.8\end{array}$ & $\begin{array}{c}3,685 \\
2.8\end{array}$ & $\begin{array}{c}3,602 \\
2.6\end{array}$ \\
\hline
\end{tabular}

Tdap=tetanus, diphtheria, and pertussis vaccine

Avg.=average 